\title{
Vertical migration in tidal currents
}

\author{
A. E. Hill \\ School of Ocean Sciences, University of Wales, Bangor, Marine Science Laboratories, Menai Bridge, Gwynedd LL59 $5 E Y$, \\ United Kingdom
}

\begin{abstract}
The principles which govern horizontal motion induced by vertical migration in oscillatory, sheared (tidal) currents are discussed. A simple model which employs linear velocity shear in the vertical, and sinusoidal vertical migration, is used to establish the fundamental ideas. For linear shear, only when tidal and migration periods exactly match is long-term unidirectional transport possible. For non-linear forms of velocity shear, unidirectional transport is also possible for migration periods which are exact multiples of the tidal period. This may be regarded as a resonant interaction between tide and migration. For migration at non-tidal periods the horizontal displacement remains bounded but the amplitude of displacements increases as tidal and migration periods become close. The time between peak horizontal displacements is usually given by the beat period between tidal and migration periods. Diel migration in $\mathrm{M}_{2}$ semi-diurnal tidal currents induces maximum horizontal excursions of no more than a few tens of kilometers and, over a duration of $15 \mathrm{~d}$, there is no net displacement. In contrast diel migration in diurnal tidal currents of the $\mathrm{K} 1$ constituent $(23.93 \mathrm{~h})$ can lead to displacements of hundreds of kilometers and the duration of effective unidirectional transport is $171 \mathrm{~d}$. A model due to Prandle (1982) which incorporates rotary tidal motion and more realistic velocity shear is presented as a tool for estimating migration-induced motion in tidal currents.
\end{abstract}

\section{INTRODUCTION}

Vertical migration is a commonly observed phenomenon in many species of marine zooplankton (Longhurst 1976). Vertical migration occurs at a variety of periods including diel (24 h; Longhurst 1976, Forward 1988) and possibly semi-diel $(12 \mathrm{~h}$; Stephenson \& Power 1988). Vertical migration also occurs at tidal periods (Wooldridge \& Erasmus 1980). The reasons for vertical migration may include predation avoidance (Stich \& Lambert 1981, Ohman et al. 1983) and bioenergetic advantages (Enright 1977). A further possibility, however, is that, in the presence of vertical current shear, vertical migration may be used to regulate horizontal position. For planktonic organisms, which would otherwise have only very limited capacity for horizontal movement, position control by vertical migration potentially provides a means to affect transport to specific locations (nursery sites for example) or conversely to promote retention in particular areas (Sinclair 1988). Even if vertical migration is not principally adapted for position control, the latter may nevertheless be an incidental effect of vertical movements in sheared flows.

It is obvious that periodic vertical migration against the background of a steady, sheared current can bring about unidirectional transport of larvae. For example, if a current is sheared in the vertical with positive flow at the surface and weaker negative flow at the sea bed, vertical migration (no matter what its period) will bring about a net larval drift in the positive direction. The long-term, sub-tidal flow in estuaries usually exhibits seaward flow at the surface and landward flow near the bottom, and is an example the kind of mean, vertical current structure which permits unidirectional transport by vertical migration (Wooldridge \& Erasmus 1980, Fortier \& Leggett 1983).

On many parts of the continental shelf, however, currents are dominated not by steady flow but by oscillatory motion of the tides. Furthermore, tidal currents are generally sheared in the vertical with flow weaker close to the sea bed because of the effect of bottom friction. Vertical migration in a (sheared, oscillatory) tidal current can also bring about long-term transport of larvae and is known as selective tidal stream transport. This happens when, for example, organisms rise to near the surface on the flood tide but descend to near the bottom (where currents are weaker) on the ebb resulting in net transport in the flood direction. Note that selective tidal stream transport depends upon the fact that the vertical migration period exactly matches the tidal period. 
If the vertical migration period and the tidal period are not equal, then, over a sufficiently long time, migration induces no net larval transport. This is because the tidal velocity cycle and the migration cycle are not 'phase-locked'. Suppose, for example, migration is diel (with $24 \mathrm{~h}$ period) and the tide is semidiurnal (12.42 $\mathrm{h}$ period). Suppose also, that on Day 1, the time at which an organism rises to the surface coincides with zero current (slack water). Exactly 24 h later, on Day 2, when the organism again reaches the surface, it is not yet slack water because this occurs 50 min later each day. Instead the current will be slightly positive, say. The organism is exposed to a slightly different state of the tide each day and, over a period of $15 \mathrm{~d}$, experiences flood and ebb currents equally at the surface. The same argument applies at any depth so that over a period of $15 \mathrm{~d}$ there is no net displacement. Note that the above physical argument is not dependent upon the precise shape of the velocity profile or upon the precise form of the vertical migration pattern (as long as its amplitude and period remain fixed). Over shorter timescales (less than $15 \mathrm{~d}$ in this case) the influence of vertical migration may be apparent. In any event the motion of a migrating organism will obviously be different from one which does not undergo migration. Can these effects be quantified?

The purpose of this paper is to set out the basic principles which govern the motion of vertically migrating organisms in oscillating vertically sheared (tidal) flows. Tidal motions are the most predictable component of flow in the ocean so that if migration-tidal interactions can be quantified this will enable such effects to be eliminated (or otherwise) from the overall pattern of movement of migrating plankton. A simple model, using sinusoidal migration and linear shear, is first used to clarify and quantify the intuitive remarks made above concerning the influence of vertical migration. More complex forms of migration and velocity shear are briefly considered before introducing a 3dimensional model of migration-tidal interaction.

\section{VERTICAL MIGRATION IN OSCILLATORY FLOWS WITH LINEAR SHEAR}

There are 2 key ingredients to the problem: an oscillatory flow in which current velocity varies with depth (sheared velocity profile) and vertical oscillatory motion of individual organisms. In order to gain an appreciation of the kind of horizontal motion induced by migration in sheared flows the simplest possible model which incorporates both shear and migration is first presented. This model employs the simplest possible velocity shear (linear) and sinusoidal migration and has the advantage of being easy to under- stand both mathematicaliy and physically. It must be stressed, however, that this first model is an idealisation designed to give physical insight into the more general problem but does not attempt to represent realistically the precise forms of either velocity shear or vertical migration actually observed in nature. In particular tidal velocity profiles in nature are usually logarithmic and certainly not linear. Nevertheless the linear shear model will enable order of magnitude estimates of horizontal migration-induced transport to be made given estimates of the gross velocity shear properties of the flow. Furthermore, given an estimate of the maximum value of shear in the flow, the linear shear results can be used to place an upper bound on the horizontal displacements induced. In some applications this alone may be useful information.

Once the basic ideas have been established with the Lnear shear model, the second part of the paper deals with how to incorporate more realistic velocity profiles and vertical migration patterns. Consider, first, the simplest model of migration-shear interaction.

\section{Flow velocity}

A simple form of tidal velocity field is used as shown in Fig 1. The tidal flow is assumed to oscillate back and forth in a straight line in the $x$ direction (rectilinear

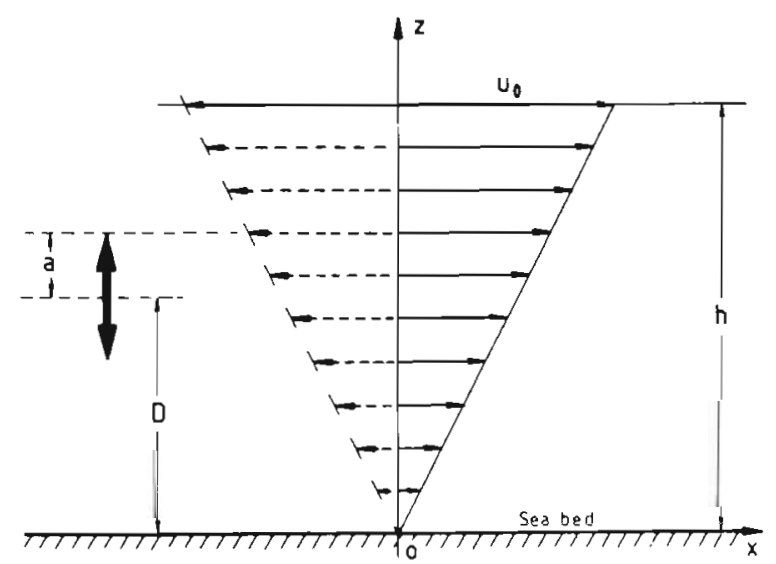

Fig. 1. Definition of the velocity profile in an oscillating flow with linear shear. Bottom velocity remains zero throughout the motion. Surface velocity amplitude is $U_{0}$. A particle representing an individual zooplankta migrates vertically with amplitude, $a_{1}$ about a mean position given by $z=D$. At $t=0$ the organism is located at $z=D$ and begins its vertical motion by moving upwards

flow) and the velocity varies linearly with depth (linear shear). For the present, current speed is taken as zero at the sea bed $(z=0)$ and the maximum possible speed $U_{0}$ occurs at the sea surface $(z=h)$. The whole profile 
oscillates back and forth at the tidal frequency. The horizontal velocity $U(z, t)$ of the flow at any height $z$ above the sea bed at time $t$ is thus given by

$$
U(z, t)=\frac{U_{0} z}{h} \sin (\omega t+\phi)
$$

where $\omega=$ angular frequency of the tidal oscillation (i.e. $\omega=2 \pi / T$ where $T$ is the tidal period); and $\phi$ is a phase angle which describes where in an oscillation cycle the motion begins (at $t=0$ ). If $\phi=0$, an oscillation cycle starts with $U(z, t)=0$ at $t=0$.

\section{Vertical migration}

Suppose that a particle (larva) executes vertical, oscillatory migration against the background of the oscillating, sheared flow described by Eq. (1). Let $z_{\mathrm{p}}(t)$ be the height of the particle above the sea bed at any time $t$ and assume that the migration has a sinusoidal form

$$
z_{\mathrm{p}}(t)=D+a \sin \left(\omega_{\mathrm{m}} t\right)
$$

where $D=$ mean height of the organism above the sea bed during the course of its migration; $a=$ amplitude of the migration (that is its maximum excursion above or below its mean height); and $\omega_{\mathrm{m}}=$ angular frequency of the migration (that is $\omega_{\mathrm{m}}=2 \pi / T_{\mathrm{m}}$ where $T_{\mathrm{m}}$ is the period of one complete migration cycle). Note that at $t=0$ the organism begins its motion at $z_{\mathrm{p}}=D$.

\section{Horizontal motion of a migrating organism in a sheared flow}

As a particle (individual organism) executes vertical migration according to Eq. (2) against the background of the velocity profile given by Eq. (1), it is moved horizontally with the velocity $U\left[z_{\mathrm{p}}(t), t\right]$ which is found at the height, $z_{p}(t)$, where the organism is located at any given time $t$. The horizontal velocity, $u_{\mathrm{p}}$ of the organism at time $t$ is then obtained by combining Eqs. (1) and (2)

$$
u_{\mathrm{p}}(t)=U\left(z_{\mathrm{p}}, t\right)=\frac{U_{0}}{h}\left[D+a \sin \left(\omega_{\mathrm{m}} t\right)\right] \sin (\omega t+\phi)
$$

and the shear, $S$, of the velocity profile may be defined as

$$
S=\frac{U_{0}}{h}
$$

Suppose that the organism begins its motion at time $t=0$ at position $(x=0, z=D)$. The horizontal displacement, $x_{\mathrm{p}}(t)$, of the particle from its initial position at subsequent times is obtained by integrating the horizontal organism velocity, thus

$$
x_{\mathrm{p}}(t)=\int u_{\mathrm{p}}(t) \mathrm{d} t+\text { constant }
$$

where the constant of integration is found from the initial condition

$$
x_{\mathrm{p}}(t)=0 \text { when } t=0
$$

The integration of Eq. (3) using Eq. (5) is straightforward and the result is

$$
\begin{aligned}
x_{\mathrm{p}}(t) & =\frac{S D}{\omega}[\cos \phi-\cos (\omega t+\phi)] \\
+ & \frac{S a}{2\left(\omega-\omega_{\mathrm{m}}\right)}\left(\sin \left[\left(\omega-\omega_{\mathrm{m}}\right) t+\phi\right]-\sin \phi\right) \\
& -\frac{S a}{2\left(\omega+\omega_{\mathrm{m}}\right)}\left(\sin \left[\left(\omega+\omega_{\mathrm{m}}\right) t+\phi\right]-\sin \phi\right)
\end{aligned}
$$

Eqs. (6) and (2) together give the position of the migrating organism $\left(x_{p}, z_{p}\right)$ relative to the origin at any time $t$. By simple rearrangement of terms, Eq. (6) can be rewritten in the alternative form

$$
\begin{aligned}
x_{p}(t)= & x_{D} \cos (\phi+\varepsilon)-\frac{S D}{\omega} \cos (\omega t+\phi) \\
& +\frac{S a}{2\left(\omega-\omega_{m}\right)} \sin \left[\left(\omega-\omega_{m}\right) t+\phi\right] \\
& -\frac{S a}{2\left(\omega+\omega_{m}\right)} \sin \left[\left(\omega+\omega_{m}\right) t+\phi\right]
\end{aligned}
$$

where

and

$$
x_{D}=\left[\left(\frac{S D}{\omega}\right)^{2}+\left(\frac{S a \omega_{\mathrm{m}}}{\left(\omega^{2}-\omega_{\mathrm{m}}^{2}\right)}\right)^{2}\right]^{1 / 2}
$$

$$
\varepsilon=\tan ^{-1}\left(\frac{a}{D} \frac{\omega_{m} \omega}{\left(\omega^{2}-\omega_{m}^{2}\right)}\right)
$$

Eq. (7) shows that the displacement $x_{p}(t)$ consists of 4 parts. The first term is a time-independent displacement and the remaining 3 terms represent a superimposed set of oscillations at frequencies $\omega, \omega-\omega_{m}$ and $\omega+\omega_{m}$.

\section{GENERAL RESULTS}

The solution, Eq. (7), for the horizontal displacement of an organism has a number of important properties. The first point to note is that vertically migrating larvae are displaced from their initial position by a mean (time-independent) distance, $\bar{x}$, given by

$$
\bar{x}=x_{D} \cos (\phi+\varepsilon)
$$

Superimposed upon this mean displacement is an oscillating (time-dependent) displacement which has 
amplitude, $A$, relative to the mean displacement where

$$
A=\left(\frac{S D}{\omega}\right)+\frac{S a}{2\left|\left(\omega-\omega_{m}\right)\right|}+\frac{S a}{2\left(\omega+\omega_{m}\right)}
$$

provided that the vertical migration frequency and the tidal frequency are not exactly equal $\left(\omega \neq \omega_{\mathrm{m}}\right)$. The case where $\omega=\omega_{\mathrm{m}}$ will be considered later. The displacement, $x_{p}(t)$, of an organism from the initial position is thus constrained to lie within the range

$$
x_{D} \cos (\phi+\varepsilon)-A \leq x_{\mathrm{p}} \leq x_{D} \cos (\phi+\varepsilon)+A
$$

provided that $\omega \neq \omega_{\mathrm{m}}$. The maximum possible horizontal range, $R$, of particle displacement is $R=2 \mathrm{~A}$.

The above result is important because it means that an organism executing vertical migration in an oscillatory shear flow [given by Eq. (1)] cannot move indefinitely away from its starting point when the migration frequency is different from the tidal frequency. Instead, the horizontal position of a migrating organism is constrained within strict limits given by Eq. (12). For given values of $S, D, a, \omega$ and $\omega_{\mathrm{m}}$, the maximum (positive) mean displacement, $\bar{x}=x_{D}$, occurs when

$$
\phi=\phi_{\max }=-\varepsilon
$$

In this case the maximum possible (positive) excursion of an organism from its initial position is

$$
x_{\max }=x_{D}+A
$$

The above features of Eq. (7) are clearly illustrated by Fig. 2 which shows the horizontal particle displacement from $x=0$ for cases when $U_{0}=1 \mathrm{~m} \mathrm{~s}^{-1}$ and $h=50 \mathrm{~m}$ so that $S=0.02 \mathrm{~s}^{-1}$. It is assumed that vertical migration extends over the full water depth and is centred at middepth $(D=h / 2, a=h / 2)$. The tidal period is taken to be that due to the principal lunar semi-diurnal constituent $\left(\mathrm{M}_{2}\right)$ and is $T=12.42 \mathrm{~h}$. In Fig. 2a the migration is diel $\left(T_{\mathrm{m}}=24.0 \mathrm{~h}\right)$. In this case the mean displacement, $\bar{x}$, from the initial position is $4.4 \mathrm{~km}$ and the maximum amplitude, $A$, of the oscillation about this mean is 8.4 $\mathrm{km}$. The maximum excursion, $x_{\max }$ of a particle from the initial position is therefore $12.8 \mathrm{~km}$. This low value clearly demonstrates the inability of diel migration to produce long-term transport in a linearly sheared flow oscillating at the $\mathrm{M}_{2}$ frequency.

Fig. $2 \mathrm{~b}$ shows the case when the period of vertical migration is semi-diel $\left(T_{\mathrm{m}}=12.0 \mathrm{~h}\right)$. The mean displacement, $\bar{x}$, is $51.8 \mathrm{~km}$ and the maximum amplitude of oscillation about the mean, $A$, is $55.3 \mathrm{~km}$ hence the
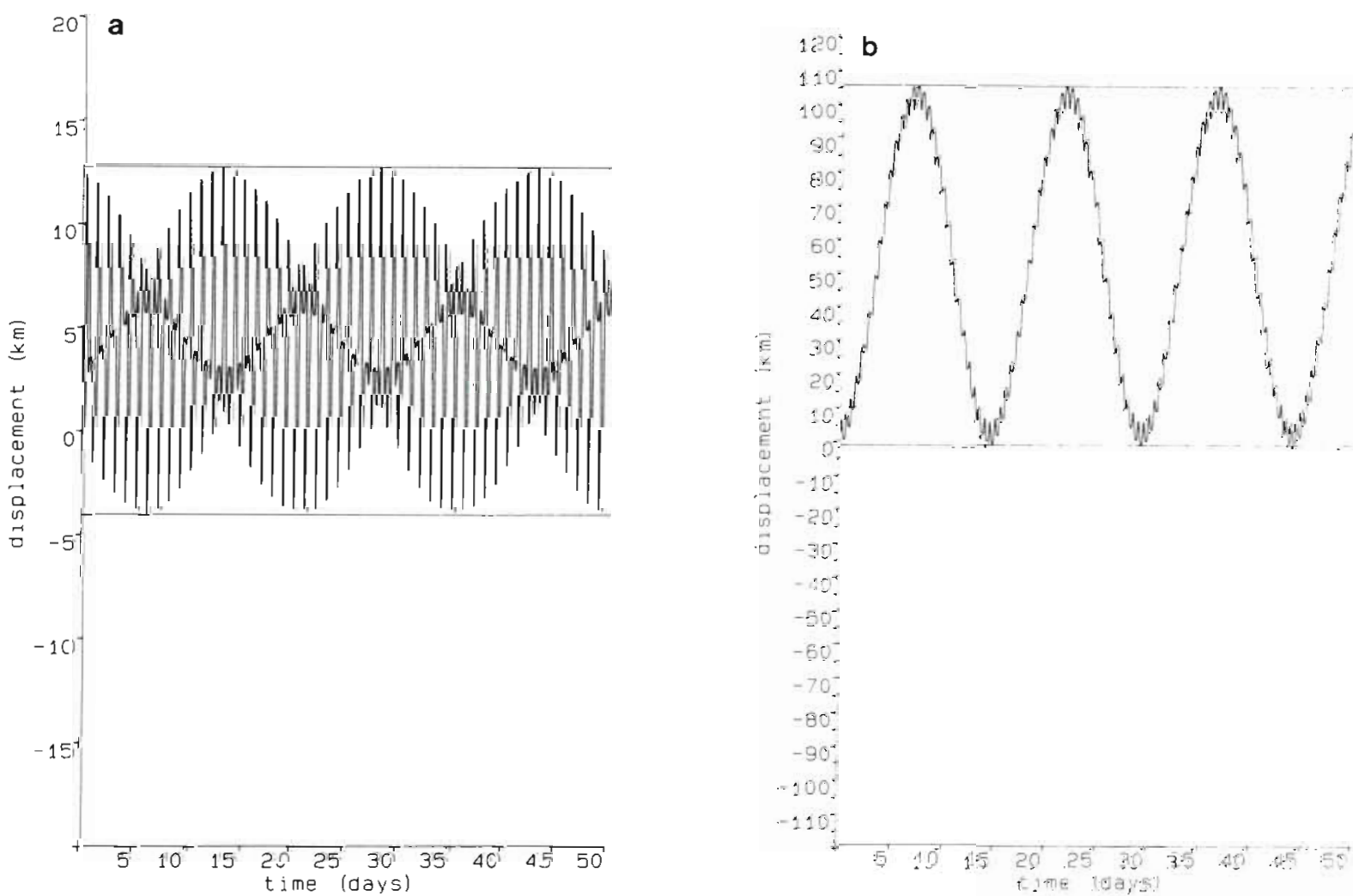

Fig. 2. (a) Diel migration, semidiumal tide. Horizontal displacement ( $\mathrm{km}$ ) of a vertically migrating organism from its initial position $x=0$. The maximum positive and negative excursions are shown by horizontal lines. $U_{0}=1 \mathrm{~m} \mathrm{~s}^{-1}, h=50 \mathrm{~m}, D=h / 2, \phi=\phi_{\mathrm{max}}=$ $-32.5^{\circ}$. Migration period. $T_{\mathrm{m}}=24 \mathrm{~h}$, tidal period, $T=12.42 \mathrm{~h}$. (b) Semi-diel migration, semidiumal tide. $U_{0}=1 \mathrm{~m} \mathrm{~s}-1, h=50 \mathrm{~m}$, $D=h / 2, \phi=\phi_{\max }=86.1^{\circ}$. Migration period, $T_{m}=12 \mathrm{~h}$, tidal period, $T=12.42 \mathrm{~h}$ 
maximum possible excursion from the initial position, $x_{\max }$ is $107.1 \mathrm{~km}$. The reason for the much larger excursions in this case is apparent in Fig. 3, considered next.

The variation of $x_{\max }$ with migration period, $T_{\mathrm{m}}$, is shown in Fig. 3 where $S, D, a$ and $\omega$ have their previ-

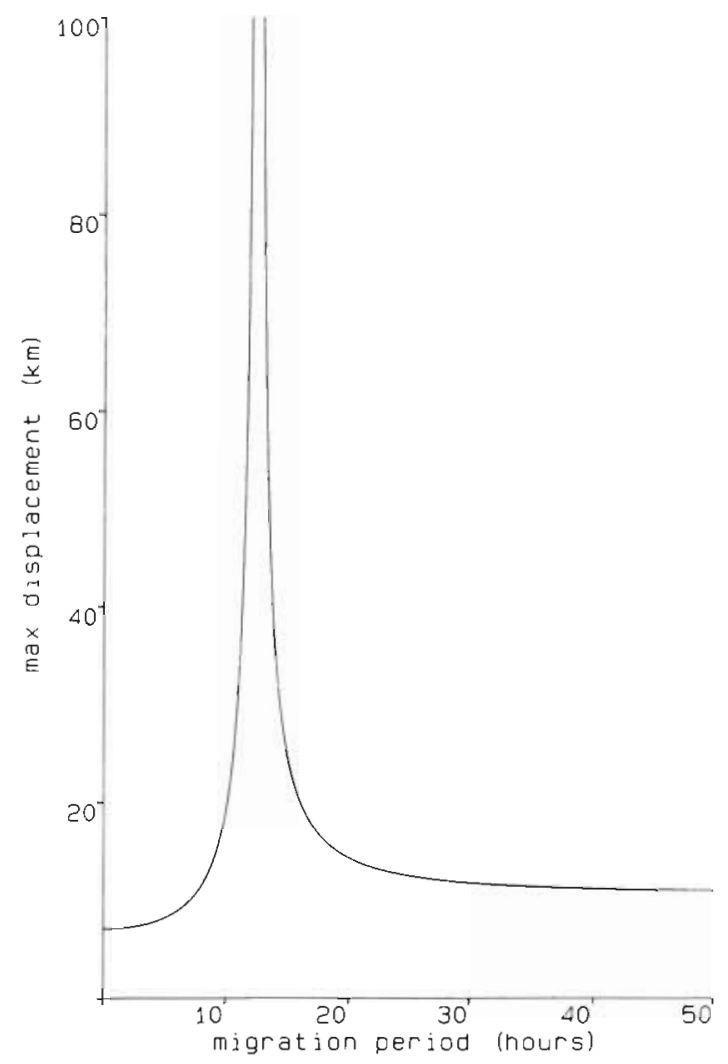

Fig. 3. Maximum horizontal displacement $(\mathrm{km})$ from the initial position $x=0$, for a range of vertical migration periods. The maximum displacement, $x_{\text {max }}$, approaches infinity as the migration period approaches the tidal period. This indicates a resonance between tidal and migration periods

ously assigned values and $T_{\mathrm{m}}$ ranges from 1 to $50 \mathrm{~h}$. For $T_{\mathrm{m}}>20 \mathrm{~h}$, the dependence of $x_{\max }$ upon $T_{\mathrm{m}}$ is rather flat at a value of about $13 \mathrm{~km}$ (as found for the case of diel migration in Fig. 2a). For migration periods close to the tidal period $(12.42 \mathrm{~h}), x_{\max }$ increases sharply and approaches infinity as $T_{\mathrm{m}}$ approaches the tidal period, $T$.

In Fig. 2a, b the time between peak horizontal displacements is about $15 \mathrm{~d}$. This time is given by $T_{B}$, where

$$
T_{\mathrm{B}}=\frac{T T_{\mathrm{m}}}{\left|\left(T-T_{\mathrm{m}}\right)\right|}
$$

and is known as the beat period between oscillations with periods $T$ and $T_{\mathrm{m}}$. The long-period beat arises because of periodic constructive and destructive interference between oscillations with slightly different periods (Neumann \& Pierson 1966). When $T=12.42 \mathrm{~h}$ and $T_{\mathrm{m}}=12.0 \mathrm{~h}, T_{\mathrm{B}}=14.78 \mathrm{~d}$. In Fig. $2 \mathrm{a}$ when $T_{\mathrm{m}}=$ $24 \mathrm{~h}$ the same period of $15 \mathrm{~d}$ between peak displacements is also found. The explanation of a $14.78 \mathrm{~d}$ beat period in the latter case involves interaction between all 3 oscillating terms in Eq. (7).

So far the case when the vertical migration frequency exactly matches the tidal frequency $\left(\omega=\omega_{\mathrm{m}}\right)$ has not been considered. Clearly, when this occurs, terms containing $\left(\omega-\omega_{\mathrm{m}}\right)$ in their denominator require special attention and this is indicative of resonant interaction between migration and tidal oscillations. In order to see what happens when $\omega=\omega_{\mathrm{m}}$ let us reconsider Eq. (6). It is the second term on the right hand side of Eq. (6) that is of special interest. This term can be dealt with, however, by noting that

$\frac{\sin \left[\left(\omega-\omega_{\mathrm{m}}\right) t+\phi\right]-\sin \phi}{\left(\omega-\omega_{\mathrm{m}}\right)} \rightarrow t \cos \phi \quad$ as $\omega_{\mathrm{m}} \rightarrow \omega$

Thus, whilst constant and oscillating terms remain in the expression for $x_{p}(t)$, a term which increases linearly with time is also introduced which takes the form

$$
x_{p}(t)=\frac{S a}{2} t \cos \phi+\text { oscillating terms }
$$

Clearly Eq. (17) no longer constrains a vertically migrating organism to a limited range of horizontal motion but, given a large enough duration $t$, the organism's displacement from its initial position is potentially unlimited. The effective long-term horizontal particle velocity induced by vertical migration is

$$
u_{\mathrm{p}}=\frac{\mathrm{d} x_{\mathrm{p}}}{\mathrm{d} t}=\frac{S a \cos \phi}{2}
$$

The maximum (positive) particle velocity and displacement occurs when $\phi=0$. In the special case where an organism migrates over the full water depth $(D=h / 2, a=h / 2)$ with $\phi=0$, the horizontal particle velocity is related to the surface tidal velocity amplitude by

$$
u_{\mathrm{p}}=\frac{U_{0}}{4}
$$

The implications of the simple vertical migration model described above are clear. For linear shear, only vertical migrations with periods that exactly match the tidal period are strictly effective in inducing long-term transport of organisms in a purely oscillatory (tidal) flow. When migration and tidal periods differ widely, such as the case of diel migration in $\mathrm{M}_{2}$ semi-diurnal tidal currents, the maximum displacement of an organism from its initial position will be no more than a few kilometers. When migration and tidal periods are close, however, larval excursions may be constrained within 
rather wider limits (up to a hundred kilometers or so). The latter point raises the possibility that diel migration may induce large particle displacements when significant diurnal tidal constituents are present. The 2 main diurnal tidal constituents are $\mathrm{K} 1(T=23.93 \mathrm{~h})$ and O1 $(T=25.82 \mathrm{~h}$; see Neumann \& Pierson 1966 for example).

Suppose that $U_{0}=0.1 \mathrm{~m} \mathrm{~s}^{-1}$ and $a, h$ and $D$ have their previously assigned values and that vertical migration is diel ( $T_{\mathrm{m}}=24 \mathrm{~h}$ ). With these values and using Eq. (14), $x_{\max }=235.7 \mathrm{~km}$ for $\mathrm{K} 1$ and $x_{\max }=10.6 \mathrm{~km}$ for O1. The large value of $x_{\max }$ for the $\mathrm{K} 1$ constituent arises because this tidal period is almost exactly $24 \mathrm{~h}$ (only $4.2 \mathrm{~min}$ shorter). Fig. 4 shows horizontal position against time

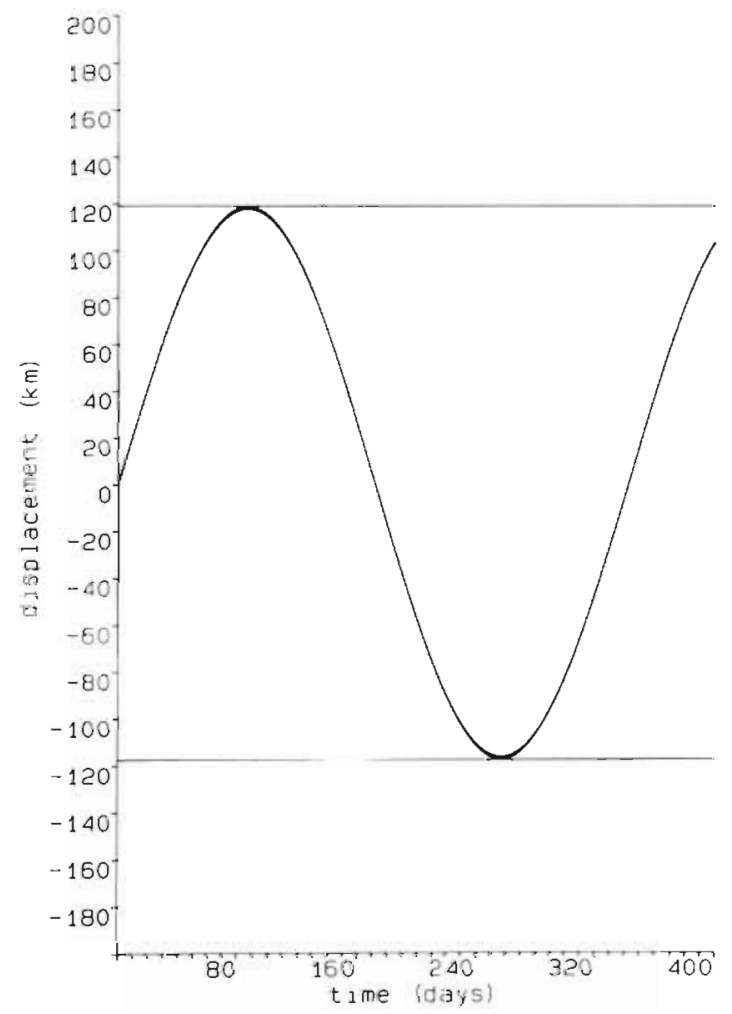

Fig. 4. Diel migration, diurnal (K1) tide. Horizontal displacement $(\mathrm{km})$ of a vertically migrating organism from its initial position $x=0$. The maximum positive and negative excursions are shown by horizontal lines. $U_{0}=0.1 \mathrm{~m} \mathrm{~s}^{-1}, h=50 \mathrm{~m}$, $D=h / 2, \phi=0^{\circ}$ Migration period, $T_{\mathrm{m}}=24 \mathrm{~h}$, tidal period, $T=$ $23.93 \mathrm{~h}$

for the case of diel migration in a $\mathrm{K} 1$ tidal current. Notice that, although the particle makes a very large excursion, it also takes a long time to make this excursion. The beat period between the migration period and the $\mathrm{K} 1$ period is $342 \mathrm{~d}$ and the time taken to reach the maximum excursion from the origin is $171 \mathrm{~d}$. The model predicts that ultimately the particle will return to the vicinity of the start point. For an organism with a complex life-cycle, including a planktonic larval phase, $170 \mathrm{~d}$ is likely to be a long time in comparison with the larval duration. In these circumstances vertical migration in a K1-period tidal current could result in effectively unidirectional transport during a short $(<171 \mathrm{~d}$ ) larval phase. The 01 constituent, on the other hand, leads to a much smaller maximum particle displacement. The inference is that only $\mathrm{K} 1$-period tidal currents are effective in inducing significant transports for diel migration.

The expression for tidal velocity shear given by Eq. (1) requires that the current is zero at the sea bed with maximum amplitude at the sea surface. This criterion can be relaxed, however, (though still retaining linear shear) without materially affecting the conclusions derived from Eq. (1). Suppose that the point where zero velocity occurs at all times during the flow (the velocity node) is at $z=h$ above the sea surface as shown in Fig. 5. In this case the velocity profile, Eq. (1), is replaced by

$$
u(z, t)=U_{0} \frac{\left(z-h_{0}\right)}{\left(h-h_{0}\right)} \sin (\omega t+\phi)
$$

At the surface $(z=h)$, the velocity amplitude remains $U_{0}$ but the profile now admits the possibility that at the

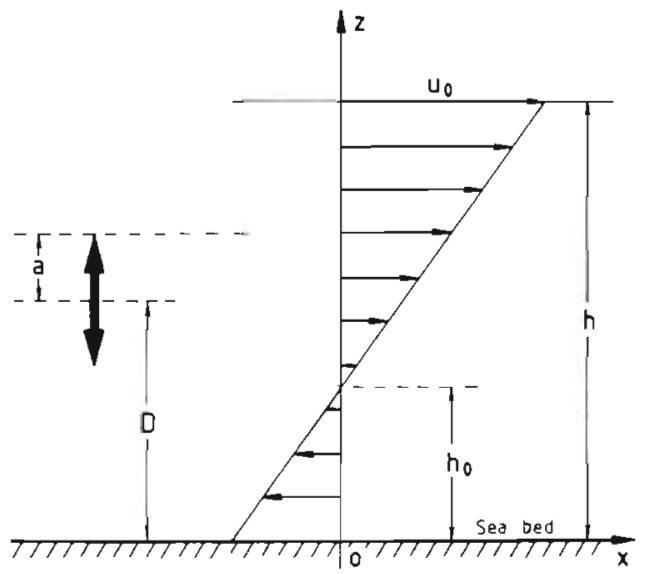

Fig. 5. Definition of the velocity profule when the velocity node occurs at an arbitrary height, $h_{0}$, above the bed

sea bed $(z=0)$ the velocity is in the opposite direction to the surface velocity. Such a profile is characteristic of baroclinic modes of tidal oscillation. The velocity profile, Eq. (1), is retrieved from Eq. (19) as the special case when $h_{0}=0$. Using Eq. (19) the analysis presented above can be repeated. The effect of using Eq. (19) instead of Eq. (1) is simply to replace $D$ in the expressions for $x_{D}, \varepsilon$ and $A$ (Eqs, $8,9 \& 11$ ) by $D-h_{0}$. Such a change does not materially affect the conclusions although it alters the quantitative results. 


\section{ASYMMETRIC VERTICAL MIGRATION}

So far a sinusoidal vertical migration pattern has been used. Migrations in nature, however, are probably more like 'square waves' with rapid ascent and descent of zooplankton occurring after long intervening periods at relatively fixed levels (Pearre 1979). Furthermore, sinusoidal migration is symmetric in time so that organisms spend equal times near the top and bottom of their migration paths. There is little reason, however, to expect that migration is symmetric. Indeed, if diel migration is basically controlled by light cues (Blaxter 1973, Forward 1988), then it is reasonable to expect that in temperate and polar latitudes, where day and night have unequal length, the time spent by organisms at depth and near the surface will also be unequal. In order to represent these effects, the sinusoidal migration pattern (Eq. 2) must be replaced

Fig. 6 shows one possible alternative form for the vertical position, $z_{\mathrm{p}}(t)$, of a particle above the sea bed. The particle spends a time $T_{\mathrm{s}}$ near the surface and time $T_{\mathrm{b}}$ near the bottom and remains at constant depth at these levels. Between these periods organisms ascend or descend with the same constant speed, $w=a / T_{w}$, where $a$ is the amplitude of the vertical migration and $T_{\mathrm{w}}$ is the time taken to move vertically through distance a. At $t=0$ the organism is located at $z=D$ and initially moves upwards. (Other possible forms of vertical $\mathrm{mi}$ gration have been pointed out by Pearre 1979.) When more complicated migration patterns (such as that shown in Fig. 6) are employed we can no longer expect a simple analytical solution for $x_{p}(t)$ and must turn to numerical integration. The horizontal larval displacement, $x_{\mathrm{p}}$, at time $t+\Delta t$ is found from the displacement at time $t$ by the relation

$$
x_{\mathrm{p}}(t+\Delta t)=x_{\mathrm{p}}(t)+U\left(z_{\mathrm{p}}(t), t\right) \Delta t
$$

The integration starts from the initial condition

$$
x_{p}(t)=0(\text { at } t=0)
$$

and $U\left(z_{\mathrm{p}}(t), t\right)$ is given by Eq. (1). The time step, $\Delta t$, has been taken as $1 \mathrm{~min}$. Fig. $7 \mathrm{a}$ shows the horizontal displacement, $x_{\mathrm{p}}(t)$, with $U_{0}=1 \mathrm{~m} \mathrm{~s}^{-1}$ and $h=50 \mathrm{~m}$ as before. The tidal period is $12.42 \mathrm{~h}$ and the tidal current phase, $\phi=0$. A rather extreme form of asymmetric vertical migration is chosen to make the point $\left(T_{\mathrm{s}}=4 \mathrm{~h}\right.$, $T_{\mathrm{b}}=16 \mathrm{~h}, T_{\mathrm{w}}=1 \mathrm{~h}$ ) and the total migration period is $24 \mathrm{~h}$ (diel). For a $16 \mathrm{~h}$ period during each migration, therefore, a larva is at $z=0$ where the horizontal velocity $U=0$. The displacement curve (Fig. 7a) is rather step-like reflecting the stepwise nature of the migration function. The displacement from the start point is limited to around $65 \mathrm{~km}$. Fig. $7 \mathrm{~b}$ shows the case of semi-diel migration in a semidiurnal current (with all other parameters as previously given). In this case the maximum displacement is about $80 \mathrm{~km}$. These results clearly indicate that the precise shape of the migration curve is immaterial to the ultimately bounded nature of the horizontal displacement.

\section{NON-LINEAR VELOCITY SHEAR}

The linear shear model provides a useful insight into the problem of migration-shear interaction. The model suffers the serious limitation, however, that it it does not properly represent the actual form of velocity shear observed in tidal currents. This and the following section concern ways in which to incorporate more realistic current shear. As a first step consider a simple modification to Eq. (1) in which the linear tidal velocity profile is represented by a power law of the form (Sutton 1953):
Fig. 6. Vertical height of a migrating organism above the sea bed for asymmetric migration. $T_{5}$ is the time spent near the surface, $T_{b}$ is the time spent near the bottom, $T_{w}$ is the time to move vertically a distance $a$

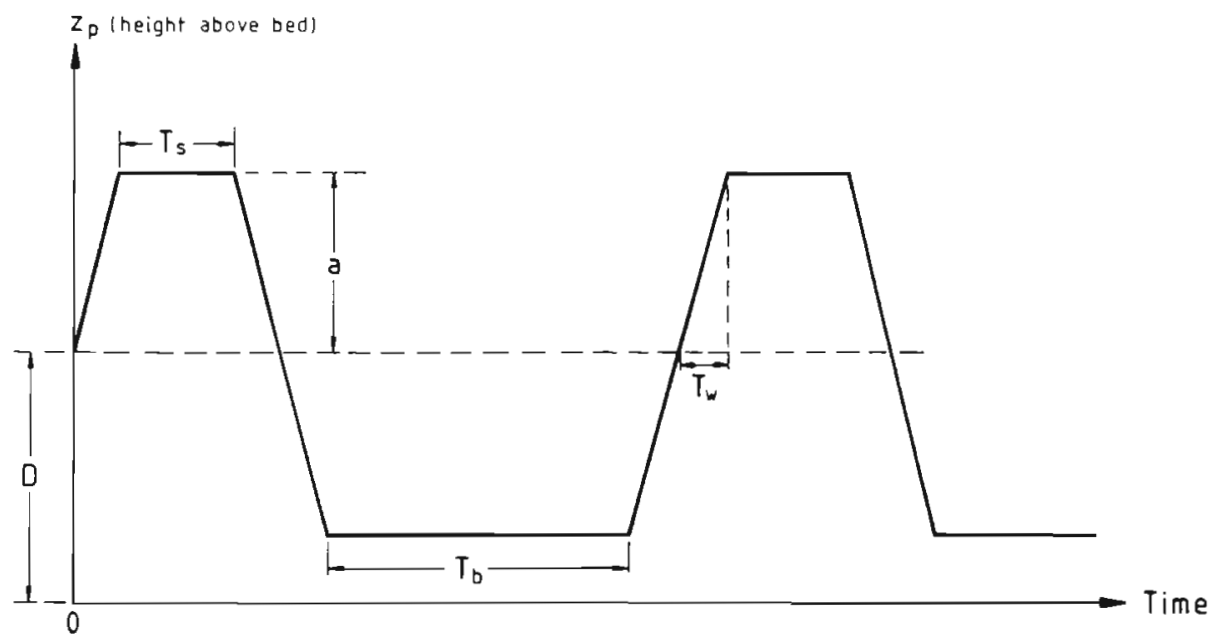



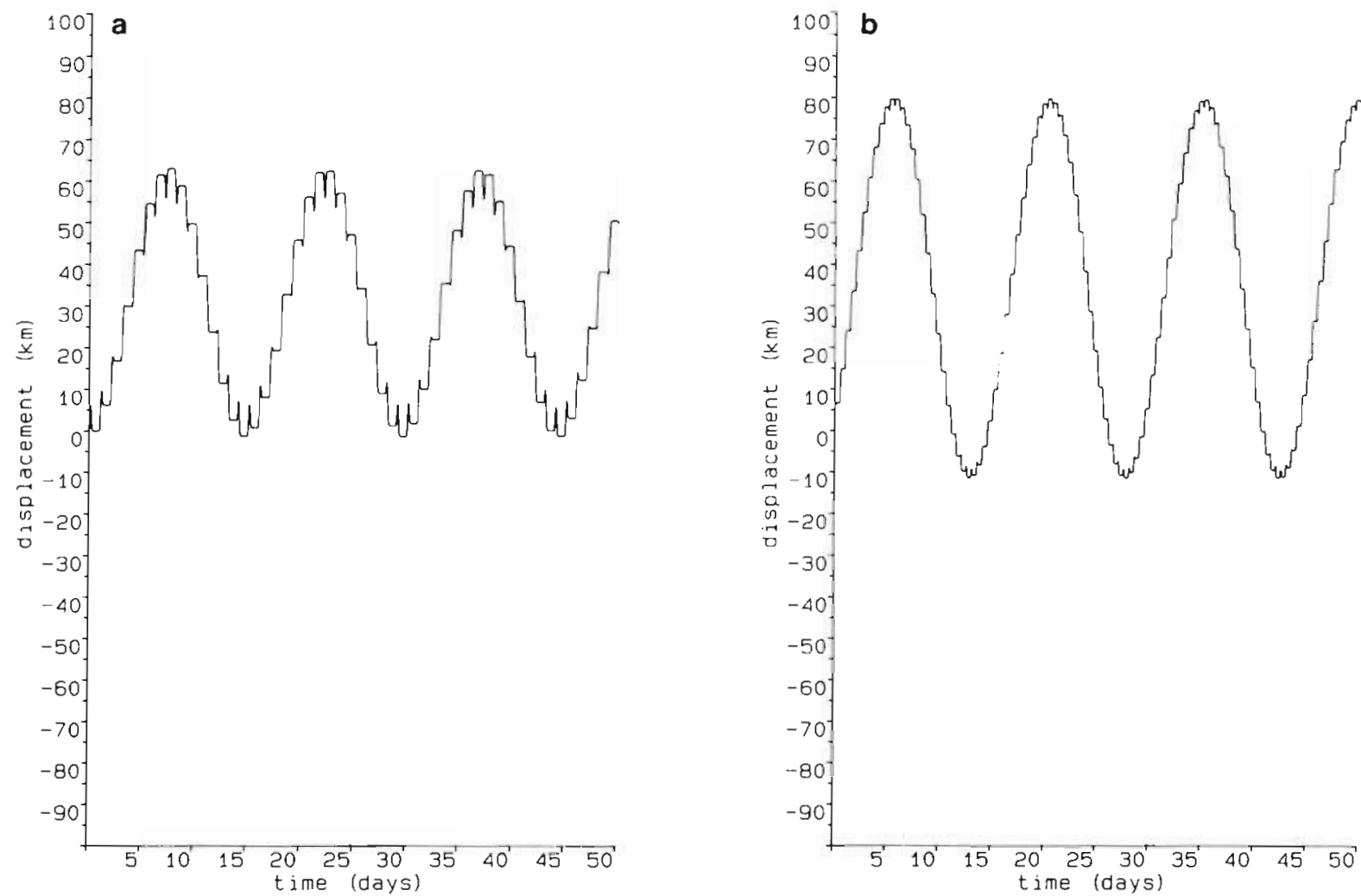

Fig. 7 Asymmetric larval migration. (a) Diel migration, semidiurnal tide. Horizontal displacement (km) of a vertically migrating organism from its initial position $x=0 . U_{0}=1 \mathrm{~m} \mathrm{~s}^{-1}, h=50 \mathrm{~m}, D=h / 2, \phi=0^{\circ}$. Migration period, $T_{\mathrm{m}}=24 \mathrm{~h}$, tidal period, $T=12.42 \mathrm{~h}$. $T_{\mathrm{b}}=16 \mathrm{~h}, T_{\mathrm{s}}=4 \mathrm{~h}, T_{\mathrm{w}}=1 \mathrm{~h}$. (b) Semi-diel migration, semidiurnal tide. $U_{0}=1 \mathrm{~m} \mathrm{~s}^{-1}, h=50 \mathrm{~m}, D=h / 2, \phi=0^{\circ}$. Migration period, $T_{\mathrm{m}}=12 \mathrm{~h}$, tidal period, $T=12.42 \mathrm{~h} . T_{\mathrm{b}}=16 \mathrm{~h}, T_{\mathrm{s}}=4 \mathrm{~h}, T_{\mathrm{w}}=1 \mathrm{~h}$

$$
U(z, t)=U_{0}\left(\frac{z}{h}\right)^{n} \sin (\omega t+\phi)
$$

Note that the previous linear profile model is retrieved as a special case when $n=1$. For turbulent boundary layers it is found that $n=1 / 3$ (Sutton 1953) and Fig. 8 a shows the shape of such a profile with $U_{0}=1 \mathrm{~m} \mathrm{~s}^{-1}$. A power law formulation is a valid, though not common, way to represent vertical current structure but is useful in this instance because it constitutes a natural extention of the linear profile model used previously and leads to a further major physicai insight into migration-tide interaction.

The horizontal velocity of a migrating organism, $u_{\mathrm{p}}$ is found as before by substituting Eq. (2) for $z$ to obtain

$u_{\mathrm{p}}=U_{0}\left(\frac{D}{h}\right)^{n}\left(1+\frac{a}{D} \sin \left(\omega_{\mathrm{m}} t\right)\right)^{n} \sin (\omega t+\phi)$

where all variables have been defined previously. Although the algebra is a good deal more complicated, Eq. (23) can be integrated using Eq. (5) to obtain $x_{p}(t)$. For the present purpose, the details of the calculation are not important. The key point to note is that the integration will produce an infinite series of terms with $\left(\omega-r \omega_{\mathrm{m}}\right)$ in their denominators where $r$ is an integer $(r=1,2,3 \ldots$ etc.). Each of these terms is rather like the third term in Eq. (7). In the same way as argued for Eq. (7) these terms permit potentially infinite, unidirectional particle displacements. Such displacements thus occur only when $r \omega_{\mathrm{m}}=\omega$, that is when $T_{\mathrm{m}}=$ $r T$ (for $r=1,2,3 \ldots$ ). Thus unlike the linear shear case, infinite displacements (or resonant interactions between tide and migration) can occur at migration periods which are exact multiples of the tidal period. For all other migration and tidal periods $x_{p}(t)$ is bounded as before. In particular diel migration in a semidiurnal $\mathrm{M}_{2}$ tide $(T=12.42 \mathrm{~h}$ ) remains strictly bounded even if tidal velocity structure has a power law form such as given by Eq. (22)

Boundary layer velocity structure is more often represented by a logarithmic profile

$$
U(z, t)=\frac{u \cdot}{\kappa} \ln \left(\frac{z+z_{0}}{z_{0}}\right) \sin (\omega t+\phi)
$$

where $z_{0}=$ roughness length scale; $u$. = friction velocity; and $k=0.4$ is von Karman's constant (Sutton 1953, Soulsby 1983). Fig. 8 b shows a logarithmic profile and 

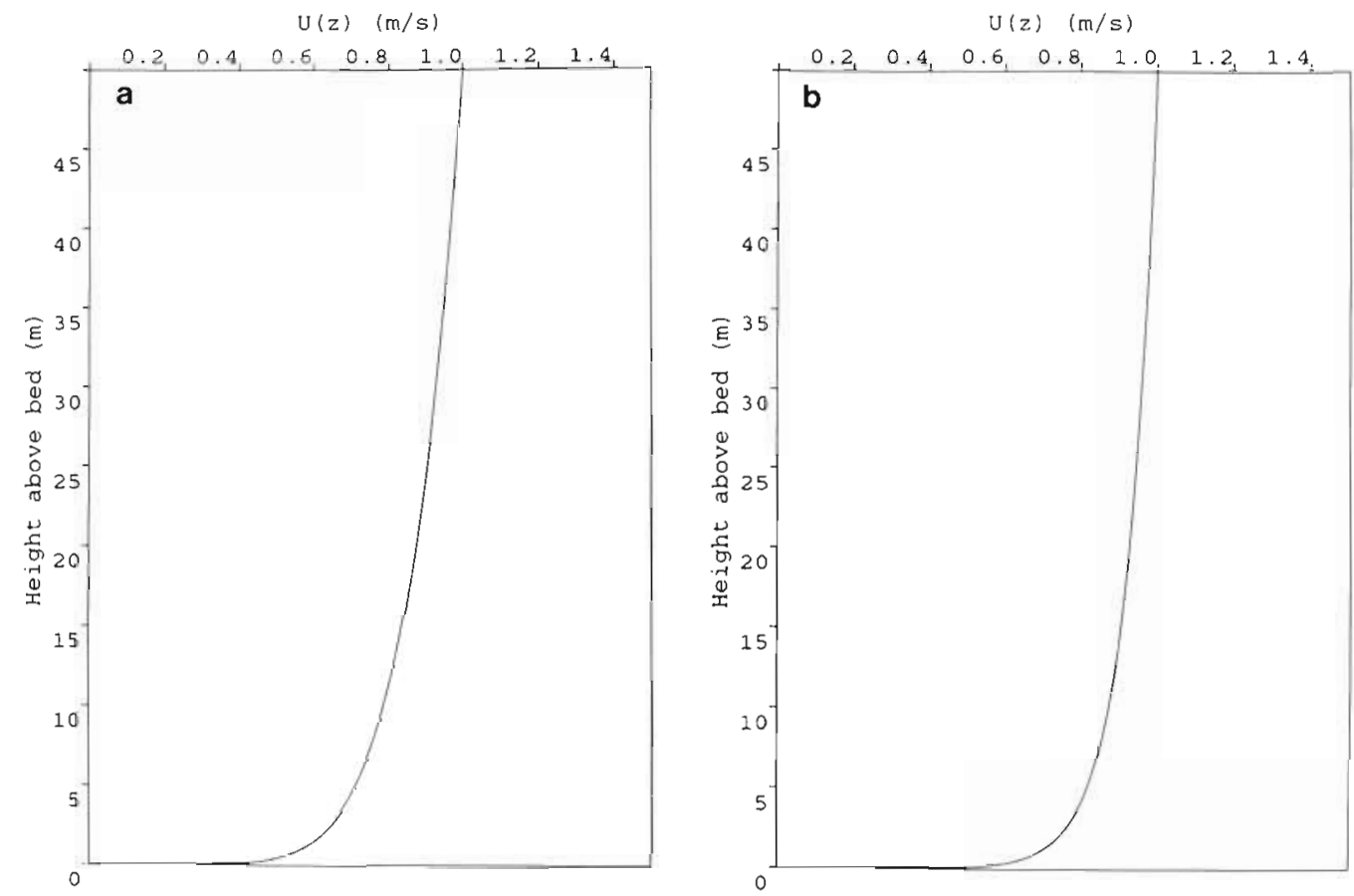

Fig. 8. (a) Vertical velocity amplitude based on the power law in Eq. (22) with $n=1 / 7 . U_{0}=1 \mathrm{~m} \mathrm{~s}^{-1}$. (b) Vertical velocity profile calculated from the logarithmic profile in Eq. $24 . u$, is chosen so that $U_{0}=1 \mathrm{~m} \mathrm{~s}^{-1}$. Roughness length, $z_{0}=2 \times 10^{-4} \mathrm{~m}$. Note sharp change in velocity in the bottom $1 \mathrm{~m}$

it closely resembles the power-law velocity structure shown in Fig. 8a. The logarithmic profile does not permit a straightforward analytical solution for $x_{p}$ which instead can be obtained by numerical integration as described in the previous section. Because virtually any shape of current profile can be approximated by a polynomial curve, the power law velocity structure provides the basic physical insight which can be applied to all non-linear profiles namely that displacements are bounded except for migration at periods which are multiples of the tidal period.

\section{THREE-DIMENSIONAL MOTION IN A TIDAL CURRENT}

All tidal currents considered so far have been rectilinear. Commonly, however, continental shelf tides are rotary because of the influence of the Earth's rotation upon water motion. We seek, therefore a physical model which includes this effect. For the present purpose a compromise is sought between a model which reproduces rotation and vertical current structure in reasonable agreement with observations and one which is sufficiently simple to be implemented fairly easily. A suitable candidate in this respect is the model of tidal current structure due to Prandle (1982). This model permits current profiles to be generated from a knowledge of a small number of readily measurable parameters. Sufficient information is given in the appendix to allow a computer program to be written to generate tidal current profiles from rather limited input data. Although this section is based on the Prandle (1982) model, the same approach can be adopted to investigate migration-induced motions based on other physical models of current structure.

Let $x$ and $y$ be coordinate axes which point eastwards and northwards respectively. Let the $z$ axis point upwards with $z=0$ at the sea bed and $z=h$ at the location of mean sea level. Suppose that $u(z, t)$ and $v(z, t)$ are horizontal velocity components in $x$ and $y$ directions respectively. The linearized equations of motion governing the flow are

$$
\begin{aligned}
& \frac{\partial u}{\partial t}-f v=-g \frac{\partial \eta}{\partial x}+A_{z} \frac{\partial^{2} u}{\partial z^{2}} \\
& \frac{\partial v}{\partial t}+f u=-g \frac{\partial \eta}{\partial y}+A_{z} \frac{\partial^{2} v}{\partial z^{2}}
\end{aligned}
$$

where $f=2 \Omega \sin \lambda$ is the Coriolis parameter; $\Omega=7.292$ $\times 10^{-5} \mathrm{~s}^{-1}$ is the angular frequency of the Earth's rotation; and $\lambda$ is the latitude of the location of interest. The acceleration due to gravity is $g=9.81 \mathrm{~m} \mathrm{~s}^{-2}$ and the sea surface elevation above or below the mean level is $\eta . A_{z}$ is the (constant) vertical eddy viscosity. The first term in each of the above equations represents the local acceleration of water with respect to the Earth's surface and the second term represents appa- 
rent acceleration induced because of the Earth's rotation. The third term in each equation is the net horizontal force per unit mass which acts on fluid because of horizontal pressure differences brought about by sea level gradients. The final term is a parameterisation of internal friction in the fluid brought about by vertically overturning turbulent eddies in the flow.

The effect of Earth rotation is to induce rotary motion of the velocity vector $(u, v)$ which consequently sweeps out an elliptical path. Such elliptical rotation of currents can be regarded as the sum of a velocity vector (of constant magnitude) which sweeps out an anticlockwise circular path and a velocity vector (again with constant magnitude) which sweeps out a circular clockwise path. The total velocity vector is thus

$u(z, t)=(u(z, t), v(z, t))=u_{a}+u_{c}=\left(u_{a}, v_{a}\right)+\left(u_{c}, v_{c}\right)$

where $\boldsymbol{u}_{\mathrm{a}}=\left(u_{\mathrm{a}}(z, t), v_{\mathrm{a}}(z, t)\right)$ is the anticlockwiserotating velocity vector; and $\boldsymbol{u}_{\mathrm{c}}=\left(u_{\mathrm{c}}(z, t), v_{\mathrm{c}}(z, t)\right)$ is the clockwise-rotating velocity vector. If the clockwiserotating vector has the greater magnitude then the total vector will rotate in a clockwise sense and vice versa. Eqs. (25) have been solved by Prandle (1982) subject to boundary conditions of zero (wind) stress at the sea surface $(z=h)$ and a linearized form of friction at the sea bed. The latter condition is given by

$$
\begin{aligned}
& A_{z} \frac{\partial u}{\partial z}=\frac{8 k}{3 \pi}|\overrightarrow{\boldsymbol{u}}| u \text { and } A_{z} \frac{\partial V}{\partial z}=\frac{8 k}{3 \pi}|\overline{\boldsymbol{u}}| V \\
& \text { (at } z=0 \text { ) }
\end{aligned}
$$

where $k$ is the non-dimensional friction coefficient for quadratic friction ( $k=0.0025)$; and $|\bar{u}|$ is the amplitude of the depth-mean current. Solutions of Eq. (25) are given in the Appendix [Eq. (A1) and Eq. (A14)]. Prandle (1982) has shown that anticlockwise and clockwise solutions for the velocity field depend only upon the parameters $S_{a}$ and $S_{c}$ respectively which are known as Strouhal numbers (for the anticlockwise and clockwise flow components respectively) and are defined as follows:

$$
S_{\mathrm{a}}=\frac{2 \pi}{h} \frac{\left|\overline{\boldsymbol{u}}_{\mathrm{a}}\right|}{(\omega+f)}
$$

and

$$
S_{\mathrm{c}}=\frac{2 \pi}{h} \frac{\left|\overline{\boldsymbol{u}}_{\mathrm{c}}\right|}{|(\omega-f)|}
$$

where $\overline{\boldsymbol{u}}_{\mathrm{a}}$ and $\overline{\boldsymbol{u}}_{\mathrm{c}}$ are the depth-averaged anticlockwise and clockwise velocity vectors respectively.

Prandle (1982) has shown that with increasing Strouhal number, the vertical velocity structure increases (i.e. the current amplitude decays more rapidly with depth). Because of the denominator $(\omega-f)$, the clockwise Strouhal number is generally larger than the anticlockwise one and hence the clockwise-rotating part of the flow decays more quickly with depth than the anticlockwise-rotating part. In order to calculate the Strouhal numbers for a given location, using Eqs. (28) and (29), estimates of the amplitudes of depthmean clockwise and anticlockwise rotating currents are required. This information is, however, readily determined from tidal ellipse characteristics which, in turn, can be obtained from current meter observations or from the output of 2-dimensional hydrodynamic tidal models such as that of Flather (1976). Suppose that the depth-mean tidal current ellipse has semi-major axis a and semi-minor axis $b$ and that the tip of the current vector sweeps out this ellipse in a clockwise sense, then it is readily shown that

$$
\left|u_{\mathrm{c}}\right|=\frac{a+b}{2}
$$

and

$$
\left|\boldsymbol{u}_{\mathrm{a}}\right|=\frac{a-b}{2}
$$

If, on the other hand, the vector rotates in an anticlockwise sense then

$$
\left|u_{a}\right|=\frac{a+b}{2}
$$

and

$$
\left|\boldsymbol{u}_{\mathrm{c}}\right|=\frac{a-b}{2}
$$

Prandle (1982) compared vertical current structure predicted by the model [Eqs. (A1) and (A14)] with observed current structure at a variety of locations on the European shelf and found good agreement. In particular, currents predicted by the model possess key features of observed tidal currents including amplitude decay and phase-advance towards the sea bed as well as rotation of the major axes of tidal ellipses in a clockwise sense towards the bed.

The boundary condition Eq. (27) permits the analytical solution given by Eqs. (A1) and (A14). Eq. (27) is a little problematical, however, because it allows nonzero velocities at the level where the boundary condition is implemented $(z=0)$. In reality flow velocities are zero at the sea bed because a no slip condition should be applied there (e.g. Soulsby 1983). The linear drag law, Eq. (27), should, therefore, strictly be regarded as applying, not right at the sea bed, but at some small distance (1 $\mathrm{m}$ say) above the bed. Flow velocity between $1 \mathrm{~m}$ and the bed is then reduced to zero in a logarithmic boundary layer. In the applications of the model presented below a logarithmic boundary layer has been coupled to the Prandle model in the bottom metre. The latter approach is justified on the grounds that, for typical roughness length scales, most of the velocity change in a logarithmic profile actually takes 
place within a metre or so of the bed (see Fig. $8 \mathrm{~b}$ for example). The effect of this coupling procedure is thus to use the steep gradient of the logarithmic curve close to the bed but, above $1 \mathrm{~m}$ where the logarithmic profile is less steep, the Prandle profile is used instead. This somewhat cumbersome procedure is a necessary consequence of calculating the velocity profile over most of the water column with the Prandle model which relies on a drag law (Eq. 27) to parametrize bottom friction. The need to splice a sharp velocity gradient onto the model near the bed could have been avoided but only at the expense of using a more sophisticated model (such as that of Soulsby 1983) from the outset.

Having defined the vertical velocity structure using the Prandle model coupled to a logarithmic boundary layer, vertical migration of a suitable form (such as Eq. $2)$ is defined. Horizontal particle displacements $\left(x_{p}, y_{p}\right)$ are then found by the time-stepping procedure given by Eq. (21).
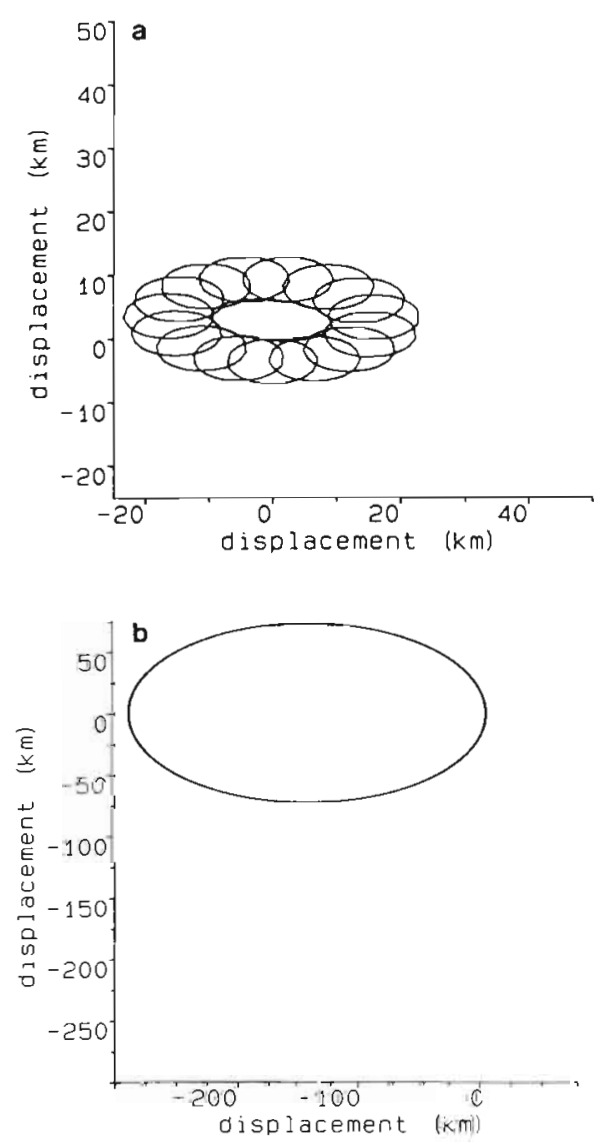

Fig. 9. Vertical migration in a sheared rotary tidal current. Horizontal displacements $(\mathrm{km})$ in $x$ and $y$ directions are shown. $h=50 \mathrm{~m}, S_{\mathrm{c}}=1000, S_{\mathrm{a}}=100$. (a) Diel migration $\left(T_{\mathrm{m}}=\right.$ $24 \mathrm{~h})$, semidiurnal $\left(\mathrm{M}_{2}\right)$ tide $(T=12.42 \mathrm{~h}) .\left|u_{c}(h)\right|=0.75 \mathrm{~m}$ $\mathrm{s}^{-1},\left|u_{\mathrm{a}}(h)\right|=0.25 \mathrm{~m} \mathrm{~s}^{-1}$. (b) Diel migration $\left(T_{\mathrm{m}}=24 \mathrm{~h}\right)$, diurnal (K1) tide $(T=23.93 \mathrm{~h}) .\left|u_{c}(h)\right|=0.075 \mathrm{~m} \mathrm{~s}^{-1},\left|u_{\mathrm{a}}(h)\right|$ $=0.025 \mathrm{~m} \mathrm{~s}^{-1}$
Fig. 9 shows the horizontal larval trajectory induced by 'square wave' migration (given by Fig. 6) coupled with a velocity field given by the Prandle model [Eqs. (A1) and (A14)]. Fig. 9a shows the case of diel (24 h) migration in a semidiurnal tidal current with surface clockwise and anticlockwise currents 0.75 and $0.25 \mathrm{~m}$ $\mathrm{s}^{-1}$ respectively. $S_{\mathrm{a}}=100$ and $S_{\mathrm{c}}=1000$ and the water depth is taken as $50 \mathrm{~m}$. An individual larva moves along a complex path and its displacement from its start point $(x=y=0$ ) remains less than $25 \mathrm{~km}$. Fig. 9b shows the case of diel $(24 \mathrm{~h})$ migration in a diurnal current with similar form to that used in the previous example except that surface clockwise and anticlockwise currents are 0.075 and $0.025 \mathrm{~m} \mathrm{~s}^{-1}$ respectively. The path of an individual larva is again fairly complicated but remains within about $200 \mathrm{~km}$ of its start point.

Although the Prandle (1982) model has a fairly straightforward analytical solution, it has a number of deficiencies which may limit its usefulness in certain circumstances. The model assumes that eddy viscosity, $A_{z}$, is constant with depth. The effects of density stratification, which cause vertical variations in eddy viscosity, are not therefore included and the model should be used with great caution in such circumstances. Rothlisberg et al. (1983) have used a model similar to that described above in a study of shrimp larvae migration in wind-driven and tidal currents in the Gulf of Carpentaria, northern Australia. Vertical current structure was derived from a model by Jordan \& Baker (1980), of which the Prandle model may be regarded as a special case. The choice of physical model to generate current structure is inevitably a compromise between a sufficiently simple model requiring the minimum number of readily measurable input parameters and one which incorporates enough of the important physical processes of the environment under consideration.

The model outlined above describes only purely oscillatory tidal motions. In principle the influence of non-tidal motions (such as wind-induced flow) can be treated by similar techniques given a suitable physical model of wind-driven current structure. The examination of such non-periodic flow components upon migration-induced motion is, however, beyond the scope of the present paper.

\section{DISCUSSION}

Many, largely descriptive, field studies have identified vertical migration in particular species. Whilst some of these have concluded that migration may influence position control, few have attempted to quantify these effects. An early attempt to do so was by Riley (1976). He used a simple model in which hypothetical tidal ellipses and residual flows were specified at 2 
levels and vertical diel migration was incorporated by allowing organisms to jump between the 2 levels. The model was used to illustrate how patches of (migrating) zooplankton grazers and (non-migrating) phytoplankton would move differentially with respect to one another. The consequent matches and mismatches in phytoplankton and zooplankton locations were postulated as a potential forcing mechanism for horizontal patchiness in plankton distributions.

Lough \& Trites (1989) have examined diel vertical migration of adult chaetognaths Sagitta elegans on the northern part of Georges Bank (off the North American east coast) and have attempted to quantify its effect upon horizontal movement. Currents in the region are dominated by semi-diurnal tidal ellipses with a superimposed eastward drift. Lough \& Trites (1989) modelled vertical migration by a 2 -level jump process rather similar to that used by Riley (1976). They assumed that, during daylight, organisms resided at or near the bottom where currents were taken as zero. During darkness organisms moved up into the water column where their horizontal motion was taken as passive drift with velocities obtained from mid-water current observations in the region. Using this model it was found that, over a period of $13 \mathrm{~d}$, vertical migration did not affect the (eastward) direction of larval movement but reduced the magnitude of the drift by $30 \%$ compared with non-migrating organisms. Over shorter periods, both magnitude and direction of drift were influenced by migration.

The migration model described in the previous section may be applied to the case studied by Lough \& Trites (1989). Major axes of the tidal ellipses are orientated northwest-southeast and surface clockwise and anticlockwise current amplitudes are taken as $0.75 \mathrm{~m}$ $\mathrm{s}^{-1}$ and $0.25 \mathrm{~m} \mathrm{~s}^{-1}$ (net clockwise rotation). Using surface velocity amplitudes in Eqs. (A26) and (A28), $S_{\mathrm{c}}=1900$ and $S_{\mathrm{a}}=97$ (strictly depth-mean velocity amplitudes should be used but velocity profiles are rather insensitive to the precise value of the Strouhal number). Water depth, $h$, is taken as $60 \mathrm{~m}$. Vertical migration is assumed to be diel ( $24 \mathrm{~h}$ ) with the form shown in Fig. 6 and with $T_{\mathrm{s}}=10 \mathrm{~h}, T_{\mathrm{b}}=10 \mathrm{~h}, T_{\mathrm{w}}=1 \mathrm{~h}$, $D=30 \mathrm{~m}$ and $a=30 \mathrm{~m}$. Migrating organisms thus penetrate into the bottom boundary layer. Particle trajectories are computed for a duration of $15 \mathrm{~d}$.

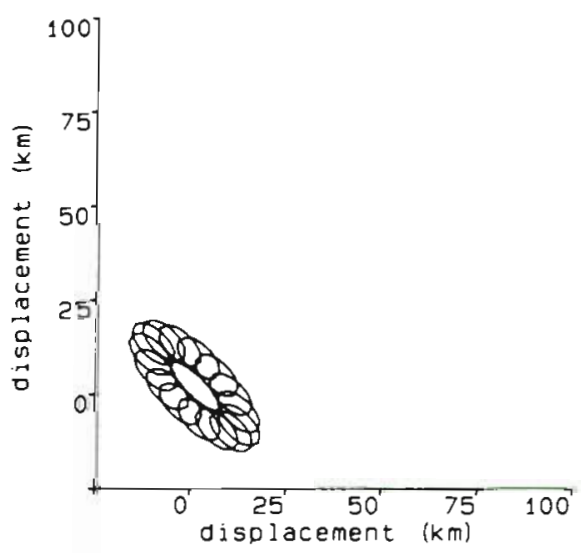

a

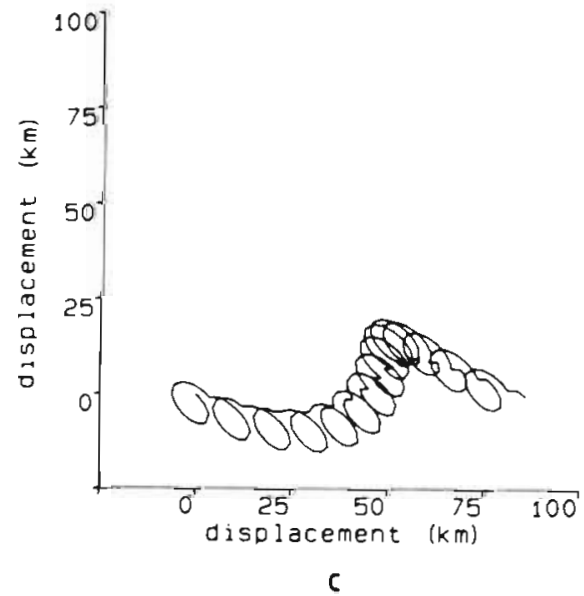

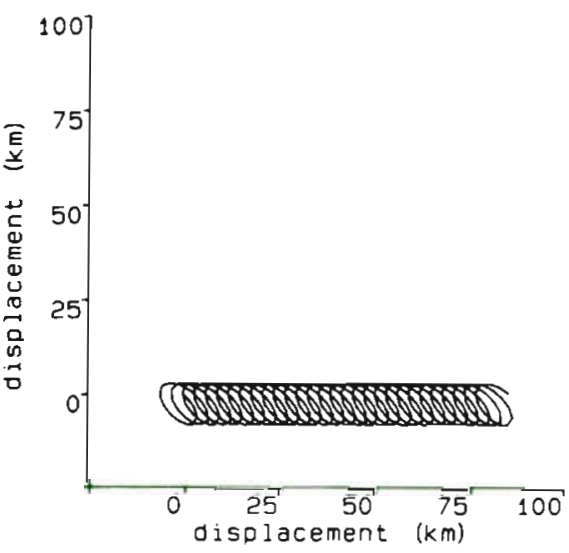

b

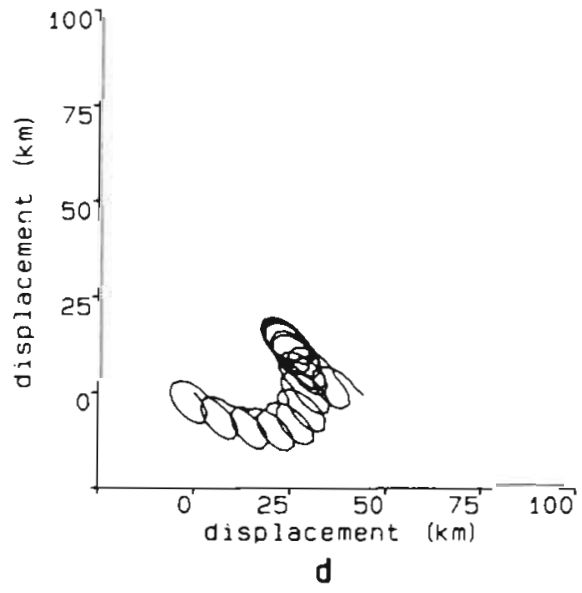

Fig. 10. Simulation of chaetognath trajectories on George's Bank. Latitude, $\lambda=42^{\circ} \mathrm{N}, h=60$ $\mathrm{m}_{1}\left|u_{\mathrm{c}}(h)\right|=0.75 \mathrm{~m} \mathrm{~s}^{-1},\left|u_{\mathrm{i}}(h)\right|$ $=0.25 \mathrm{~m} \mathrm{~s}^{-1}, S_{\mathrm{c}}=1900, S_{\mathrm{a}}=97$ $T_{\mathrm{b}}=10 \mathrm{~h}, T_{\mathrm{s}}=10 \mathrm{~h}, T_{\mathrm{w}}=1 \mathrm{~h} . T_{\mathrm{m}}$ $=24$ h. $a=30 \mathrm{~m}, D=30 \mathrm{~m}, T=$ $12.42 \mathrm{~h}$. Tidal ellipses are orientated northwest-southeast. Organisms start their motion at the point $(0,0)$. Vertical and horizontal axes point northward and eastward respectively. (a) Vertical migration in tidal currents only. (b) No migration (organisms remain at the surface) and constant eastward residual current $5.7 \mathrm{~km} \mathrm{~d}^{-1}$ (c) Vertical migration and constant eastward residual current $5.7 \mathrm{~km} \mathrm{~d}^{-1}$ at all depths. (d) Vertical migration and linearly sheared eastward residual current. Surface residual $5.7 \mathrm{~km} \mathrm{~d}^{-1}$, bottom residual $=$ $0 \mathrm{~km} \mathrm{~d} 1$ 
Fig. 10a shows the trajectory of a vertically migrating organism when tidal motions alone are considered. The organism moves along a complicated path executing a closed loop over $15 \mathrm{~d}$ (the beat period between migration and tidal periodsj. The range of horizontal motion is about $40 \mathrm{~km}$. Fig. $10 \mathrm{~b}$ includes the effect of a constant, eastward residual flow of $5.7 \mathrm{~km} \mathrm{~d}^{-1}$ which is observed in the region. In this case the organism does not migrate but remains at the sea surface throughout the motion. Net organism displacement in the eastward direction is $86 \mathrm{~km}$. In Fig. 10c the organism migrates vertically and is subject to a constant eastward residual current of $5.7 \mathrm{~km} \mathrm{~d}^{-1}$ at all depths. The net eastward displacements in Fig. $10 \mathrm{~b}$ and $\mathrm{c}$ are equal $(86 \mathrm{~km}$ ) because over $15 \mathrm{~d}$ there is no contribution from the tidal component of flow. In Fig. 10d the residual current varies linearly with depth from $5.7 \mathrm{~km} \mathrm{~d}^{-1}$ at the surface to zero at the sea bed (all currents are thus zero at the bed). In this case a migrating organism progresses eastward at the depth-mean residual speed and thus moves only half the distance it does in the previous 2 cases. This result is consistent with that of Lough \& Trites (1989). They used a migration schedule in which larvae experienced zero motion for $8 \mathrm{~h}$ and a mean effective eastward flow of $5.7 \mathrm{~km} \mathrm{~d}^{-1}$ for the remainder of the time. Consequently the net displacement of migrating organisms was found to be reduced by about one-third compared to that experienced by non-migrating organisms (with the tidal component making a negligible contribution over $13 \mathrm{~d}$ ). The above example illustrates a case where migration-tidal interaction plays no effective role in the horizontal motion of organisms. Only migration interaction with the residual flow affects horizontal transport. On timescales shorter than $15 \mathrm{~d}$, migration-tidal interaction brings about the small north-south displacements of the trajectory. Migration- $\mathrm{M}_{2}$ tidal interaction is, therefore, not a mechanism that promotes retention on Georges Bank (or similar locations) against prevailing mean currents.

A notable attempt to quantify the influence of vertical migration was due to Rothlisberg et al. (1983) Penaeid shrimp larvae are released into the offshore waters of the Gulf of Carpentaria, Australia, and, after a planktonic period of 2 to $3 \mathrm{wk}$, must enter an estuarine environment. Rothlisberg et al. (1983) used a model which was a hybrid of a conventional 2-dimensional, depth-averaged hydrodynamic model and a model due to Jordan \& Baker (1980) to establish vertical tidal current structure over the Gulf of Carpentaria. Their model also incorporated mean wind-driven flows inferred from the 2-dimensional, hydrodynamic model. In contrast to the previous case, horizontal displacements of shrimp larvae induced by vertical migration in tidal currents were found to be a significant part of the motion. The Gulf of Carpentaria is a region where diurnal tidal constituents are dominant so that diel migration may be expected to bring about significant larval transport. Church \& Forbes (1981) have shown that tides in the southern Gulf of Carpentaria are dominated by a north-south component (and hence are approximately rectilinear). The amplitudes of both $\mathrm{K} 1$ and $O 1$ constituents are between 0.1 and $0.3 \mathrm{~m} \mathrm{~s}^{-1}$ in the region.

In this case the linear shear model can usefully be employed to give an estimate of horizontal migrationinduced motion. Assuming a velocity profile given by Eq. (1) and that larvae migrate over the full water column depth ( $a=h / 2$ and $D=h / 2)$, Eq. (11) may be rewritten as

$$
A=\frac{U_{0} T}{4 \pi}\left(\frac{\left|T_{\mathrm{m}}{ }^{2}-T^{2}\right|+T_{\mathrm{m}}^{2}}{\left|T_{\mathrm{m}}{ }^{2}-T^{2}\right|}\right)
$$

where $A=$ maximum amplitude of horizontal larval excursions; $T_{\mathrm{m}}=$ migration period; and $T=$ tidal period. Note that, in this form, the result is independent of the local water depth. Using Eq. (31) for O1, the maximum range of horizontal movement, $R=2 \mathrm{~A}=10$ to $32 \mathrm{~km}$. For $\mathrm{K} 1$ the maximum range of movement is 246 to $710 \mathrm{~km}$ for $U_{0}$ in the range 0.1 to $0.3 \mathrm{~m} \mathrm{~s}^{-1}$ (see Fig. 4). The time over which this maximum range of movement is achieved, however, is about $170 \mathrm{~d}$ which is much longer than the planktonic larval phase (2 to 3 wk). For migration in a $\mathrm{K} 1$ tidal current with surface velocity $0.1 \mathrm{~m} \mathrm{~s}^{-1}$ the maximum possible displacement that can occur in a $20 \mathrm{~d}$ period is about $50 \mathrm{~km}$ (which can be inferred from the steepest part of the curve in Fig. 4). For K1 currents with velocities in the range 0.1 to $0.3 \mathrm{~m} \mathrm{~s}^{-1}$, therefore, the maximum expected displacement is 50 to $150 \mathrm{~km}$ in $20 \mathrm{~d}$. In the Gulf of Carpentaria the adult shrimp distribution is confined to within $130 \mathrm{~km}$ of the coast so that diel migration in tidal currents could permit inshore movement of larvae within the duration of their planktonic phase. This concurs with the conclusion reached by Rothlisberg et al. (1983) who argued that this may the limiting condition that controls the offshore distribution of adults.

The last example highlights an interesting feature of diel migration in diurnal tidal currents. The beat period of $\mathrm{K} 1$ and $24 \mathrm{~h}$ migration is $342 \mathrm{~d}$ so that unidirectional transport occurs for a duration of $171 \mathrm{~d}$ (or about 6 mo; see Fig. 4 for example). Because $342 \mathrm{~d}$ is a little less than $365.25 \mathrm{~d}$ ( $1 \mathrm{yr}$ ), the time window when positive transport occurs moves back by about $23 \mathrm{~d}$ each year. Thus, if positive transport occurs initially for the first half of the year, then, after about $7 \mathrm{yr}$, positive transport will occur in the second half of the year. This suggests that, for organisms reliant upon migration-tidal interaction for recruitment, short spawning periods at fixed times each year is not a good strategy and would lead to a $7 \mathrm{yr}$ cycle of recruitment failure and success. 


\section{APPENDIX}

The velocity vector at any height $z$ above the sea bed sweeps out an elliptical path which may be considered to be made up of the sum of an anticlockwise-rotating vector $\boldsymbol{u}_{\mathrm{a}}=\left(u_{\mathrm{a}}, v_{\mathrm{a}}\right)$ and a clockwise-rotating vector $\boldsymbol{u}_{\mathrm{c}}=\left(u_{c}, v_{c}\right)$. These vectors can be represented on the complex plane by complex numbers

and

$$
\boldsymbol{u}_{\mathrm{a}}=\mathrm{u}_{\mathrm{a}}+i v_{\mathrm{a}}
$$

$$
u_{\mathrm{c}}=u_{\mathrm{c}}+i v_{\mathrm{c}}
$$

where $i=\sqrt{-1}$. The forms of these components are considered in turn.

\section{Anticlockwise-rotating component}

Prandle (1982) has demonstrated that the solution of Eq. (25) subject to the surface and bottom boundary conditions and $A_{z}=$ constant is for the anticlockwiserotating flow component

$\boldsymbol{u}_{\mathrm{a}}=u_{\mathrm{a}}+i v_{\mathrm{a}}=$

$\left[A_{\mathrm{a} 1} \exp \left(b_{\mathrm{a}} z\right)+A_{\mathrm{a} 2} \exp \left(-b_{\mathrm{a}} z\right)+C_{\mathrm{a}}\right] \exp (i \omega t)$

where $A_{a 1}, A_{a 2}, C_{a}$ and $b_{a}$ are all complex constants and $\omega$ is the (real) tidal angular frequency. Let $Y_{a}$ be the real number

$$
Y_{\mathrm{a}}=\left(\frac{\omega+f}{A_{z}}\right)^{1 / 2} h
$$

then the complex number $b_{\mathrm{a}}$ is defined as

$$
b_{\mathrm{a}}=\frac{Y_{\mathrm{a}}}{\sqrt{2}} \frac{(1+i)}{h}
$$

Also define the real number, $J_{a}$, where

$$
J_{\mathrm{a}}=\frac{3 \pi\left[A_{z}(\omega+f)\right]^{1 / 2}}{8 k\left|\overline{\mathbf{u}}_{\mathrm{a}}\right|}
$$

and $k$ is the dimensionless quadratic friction coefficient ( $k=0.0025)$, then the complex number $j_{\mathrm{a}}$ may be defined as

$$
j_{a}=\frac{J_{a}}{\sqrt{2}}(1+i)
$$

With these quantities defined it may be shown that

$$
A_{\mathrm{a} 1}=\frac{C_{\mathrm{a}}}{\alpha_{\mathrm{a}}} \exp \left(-2 b_{\mathrm{a}} h\right)
$$

and

$$
A_{\mathrm{a} 2}=\frac{C_{\mathrm{a}}}{\alpha_{\mathrm{a}}}
$$

where

$$
\alpha_{\mathrm{a}}=\left\{\left(j_{\mathrm{a}}-1\right) \exp \left(-2 b_{\mathrm{a}} h\right)-\left(j_{\mathrm{a}}-1\right)\right\}
$$

Collecting together the real and imaginary parts of
Eq. (A8), the complex number $\alpha_{a}$ can be written in the form

$$
\alpha_{\mathrm{a}}=\alpha_{\mathrm{ar}}+i \alpha_{\mathrm{ar}}
$$

Note also that $\exp \left(-2 b_{\mathrm{a}}\right)$ may be expressed in real and imaginary parts as

$\exp \left(-2 b_{a} h\right)=$
$\exp \left(-\sqrt{2} Y_{a}\right)\left[\cos \left(\sqrt{2} Y_{a}\right)-i \sin \left(\sqrt{2} Y_{a}\right)\right]$

The anticlockwise surface current velocity $\boldsymbol{u}_{a}(h)$ at $t=0$ is controlled by the value given to the constant $C_{a}$. If the surface current is specified then the constant $C_{a}$ is given by

$$
C_{\mathrm{a}}=\frac{\boldsymbol{u}_{\mathrm{a}}(h, 0) \alpha_{\mathrm{a}}}{\left(2 \exp \left(-b_{\mathrm{a}} h\right)+\alpha_{\mathrm{a}}\right)}
$$

If the complex number in the denominator of Eq. (A11) is denoted by $\beta$, where

$$
\beta=\beta_{\mathrm{I}}+i \beta_{\mathrm{i}}=\left(2 \exp \left(-b_{\mathrm{a}} h\right)+\alpha_{\mathrm{a}}\right)
$$

then the real and imaginary parts of $C_{a}$ are given by

$$
C_{\mathrm{a}}=C_{\mathrm{ar}}+i C_{\mathrm{ai}}=\frac{\left(u_{\mathrm{ar}}+i u_{\mathrm{ai}}\right)\left(\alpha_{\mathrm{ar}}+i \alpha_{\mathrm{a} i}\right)\left(\beta_{\mathrm{r}}-i \beta_{1}\right)}{\left(\beta_{r}^{2}+\beta_{1}^{2}\right)}
$$

where subscripts $r$ and $i$ denote real and imaginary parts respectively. Thus if the real and imaginary parts of the surface (anticlockwise-rotating) velocity at $t=0$ are specified as $u_{\mathrm{ar}}$ and $u_{\mathrm{ai}}$ then expansion of the numerator of Eq. (A13) will permit the real and imaginary parts of $C_{a}$ to be found. Once the real and imaginary parts of $C_{a}$ are known, $A_{a 1}$ and $A_{a 2}$ are readily expressed in real and imaginary parts also. Using these results the real and imaginary terms on the right hand side of Eq. (1) can be collected together thereby giving the values of $u_{a}$ and $v_{a}$.

\section{Clockwise-rotating component}

For clockwise-rotating currents the solution of Eq. (25) is

$\boldsymbol{u}_{\mathrm{c}}=u_{\mathrm{c}}+i v_{\mathrm{c}}=$

$\left[A_{c 1} \exp \left(b_{c} z\right)+A_{c 2} \exp \left(-b_{c} z\right)+C_{c}\right] \exp (-i \omega t)$

Let $Y_{c}$ be the real number

$$
Y_{c}=\left(\frac{|f-\omega|}{A_{z}}\right)^{1 / 2} h
$$

Also define the real number, $J_{c}$ where

$$
J_{c}=\frac{3 \pi\left[A_{z}|(f-\omega)|\right]^{1 / 2}}{8 k\left|\bar{u}_{c}\right|}
$$

There are 2 cases to be considered for clockwiserotating currents: 
Case 1: $f>\omega$. (Tidal period greater than inertial period.) In this case the complex number $b_{c}$ takes the value

$$
b_{c}=\frac{Y_{c}}{\sqrt{2}} \frac{(1+i)}{h}
$$

and the complex number $j_{c}$ may be defined as

$$
j_{c}=\frac{J_{c}}{\sqrt{2}}(1+i)
$$

Case 2: $\boldsymbol{f}<\omega$. (Tidal period less than inertial period.) In this case the complex number $b_{c}$ takes the value

$$
b_{c}=\frac{Y_{c}}{\sqrt{2}} \frac{(i-1)}{h}
$$

and the complex number $j_{c}$ may be defined as

$$
j_{\mathrm{c}}=\frac{J_{\mathrm{c}}}{\sqrt{2}}(i-1)
$$

With these quantities defined it may be shown that

and

$$
A_{\mathrm{cl}}=\frac{C_{\mathrm{c}}}{\alpha_{\mathrm{c}}} \exp \left(-2 b_{\mathrm{c}} h\right)
$$

$$
A_{c 2}=\frac{C_{c}}{\alpha_{c}}
$$

$$
\alpha_{c}=\left\{\left(j_{c}-1\right) \exp \left(-2 b_{c} h\right)-\left(j_{c}-1\right)\right\}
$$

Again the surface clockwise current velocity $\boldsymbol{u}_{\mathrm{c}}(h)$ is controlled by the value given to the constant $C_{c}$. If the surface current is specified then $C_{C}$ is given by

$$
C_{c}=\frac{u_{\mathrm{c}}(h) \alpha_{c}}{\left(2 \exp \left(-b_{c} h\right)+\alpha_{\mathrm{c}}\right)}
$$

where the appropriate values of $b_{c}$ and $j_{c}$ are used depending upon whether Case 1 or Case 2 applies. Note that diurnal tidal periods correspond to Case 1 whereas for mid and low latitudes Case 2 applies for semidiurnal tidal periods. The real and imaginary parts of $C_{c}$ are found in a similar manner to that described for $C_{\mathrm{a}}$ and hence the real and imaginary parts of Eq. (A14), i.e. $u_{c}$ and $v_{c}$, can be found.

Eddy viscosity is parameterised in terms of the mean current amplitude $|\overline{\boldsymbol{u}}|$ (clockwise or anticlockwise):

$$
A_{z}=\gamma|\bar{u}| h
$$

(see Prandle 1982) where $\gamma$ is a dimensionless constant $(\gamma=0.0012)$. Physically this states that as the mean current amplitude increases and as the total water depth, $h$, increases, the eddy viscosity, $A_{z}$ (a measure of the size of turbulent eddies in the flow) also increases. In general the parameterisation of internal friction in the ocean using eddy viscosity is a problematic area of physical oceanography. Treatment of eddy viscosity as a constant through the water column is a common simplification which is rarely justified. The form that vertical eddy viscosity profiles should take is far from clear, however, and the modern approach is to determine eddy viscosity at each depth and time from the computed turbulent energy dissipation rate (turbulence closure).

Using the relation (A25) it may be shown that if

$$
S_{a}=\frac{2 \pi\left|\bar{u}_{a}\right|}{(\omega+f)}
$$

then

$$
Y_{\mathrm{a}}=\left(\frac{2 \pi}{\gamma S_{\mathrm{a}}}\right)^{1 / 2} \text { and } J_{\mathrm{a}}=\left(\frac{9 \pi \gamma^{3}}{32 k^{2}} S_{\mathrm{a}}\right)^{1 / 2}
$$

and if

$$
S_{c}=\frac{2 \pi\left|\bar{u}_{c}\right|}{(|f-\omega|)}
$$

then

$$
Y_{\mathrm{c}}=\left(-\frac{2 \pi}{\gamma S_{\mathrm{c}}}\right)^{1 / 2} \text { and } J_{\mathrm{c}}=\left(\frac{9 \pi \gamma^{3}}{32 k^{2} S_{c}}\right)^{1 / 2}
$$

Thus, given values of clockwise and anticlockwise Strouhal numbers $Y_{a}, Y_{c}, J_{a}$ and $J_{c}$ can be evaluated and hence the values of all the unknown constants in Eqs. (A1) and (A14) can be determined.

Acknowledgements. I thank Prof. E. Naylor for his helpful comments on this manuscript. Frank Evans of the Dove Marine Laboratory stimulated me to think about asymmetric forms of vertical migration. One of the referees prompted me to think more closely about migration in non-linear current profiles

\section{LITERATURE CITED}

Blaxter, J. H. S. (1973). Monitoring the vertical movement and light responses of herring and plaice larvae. J. mar biol. Ass. U.K. 53: 635-647

Church, J. A., Forbes, A. M. G. (1981). Non-linear model of the tides in the Gulf of Carpentaria. Aust. J. mar Freshwat. Res. 32: 685-697

Enright, J. T (1977). Diurnal vertical migration: adaptive significance and timing. Part 1 . Selective advantage: a metabolic model. Limnol. Oceanogr 22: 856-872

Flather, R. A. (1976). A tidal model of the North-West European continental shelf. Mém. Soc. R. Sci. Liège, Ser 6, 10 141-164

Fortier, L., Leggett, W. C. (1983). Vertical migration and transport of larval fish in a partially mixed estuary. Can. J. Fish. Aquat. Sci. 40: 1543-1555

Forward, R. B. (1988). Diel vertical migration: zooplankton photobiology and behaviour Oceanogr. mar. Biol. A. Rev. 26: 361-393

Jordan, T. F., Baker, J. R. (1980). Vertical structure of timedependent flows dominated by friction in a well mixed fluid. J. phys. Oceanogr. 10: 1091-1103

Longhurst, A. R. (1976). Vertical migration. In: Cushing, A. R. Walsh, J. (eds.) Ecology of the seas. Blackwell Scientific, Oxford, p. 116-137 
Lough, R. G., Trites, R. W. (1989). Chaetognaths and oceanography on Georges Bank. J. mar Res. 47: 343-369

Nelumann, G., Pierson, W J. (1966). Principles of physical oceanography. Prentice-Hall, Englewood Cliffs

Ohman, M. D., Frost, B. W., Cohen, E. B. (1983). Reverse diel migration: an escape from invertebrate predators. Science 220: $1404-1407$

Pearre, S. (1979). Problems of detection and interpretation of vertical migration. J. Plankton Res. 1. 29-44

Prandle, D. (1982). The vertical structure of tidal currents and other oscillatory flows. Cont. Shelf Res. 1: 191-207

Riley, G. A. (1976). A model of plankton patchiness. Limnol. Oceanogr. 21: 873-880

Rothlisberg, P., Church, J. A., Forbes, A. M. G. (1983). Modelling the advection of vertically migrating shrimp larvae. J. mar. Res. 41. 511-538

Sinclair, M. (1988). Marine populations: an essay on popula-

This article was submitted to the editor tion regulation and speciation. Washington Sea Grant/ University of Washington Press, Seattle

Soulsby, R. L. (1983). The bottom boundary layer of shelf seas In: Johns, B. (ed.) Physical oceanography of coastal and shelf seas. Elsevier Oceanography Series 35: 189-266

Stephenson, R. L., Power, M. J. (1988). Semi-diel vertical movements in Atlantic herring Clupea harengus larvae: a mechanism for larval retention? Mar. Ecol. Prog. Ser. 50: $3-11$

Stich, H.-B., Lambert, W. (1981). Predator evasion as an explanation of diurnal vertical migration by zooplankton. Nature, Lond. 293: 396-398

Sutton, O. G. (1953). Micrometeorology. McGraw-Hill, New York

Wooldridge, T., Erasmus, T. (1980). Utilization of tidal currents by estuarine zooplankton. Estuar. coast. mar. Sci. 11: $107-114$

Manuscript first received: December 10, 1990

Revised version accepted: May 24, 1991 